\title{
Urinary tract infection among neonatal sepsis of late-onset in Cipto Mangunkusumo Hospital
}

\author{
Novie Amelia, MD; Idham Amir, MD; Partini P Trihono, MD, MM(Paed)
}

\begin{abstract}
Background Urine culture, as part of a full septic work-up for late-onset neonatal sepsis, was not routinely done in the Neonatal Ward at Cipto Mangunkusumo Hospital, and as of today, the prevalence of urinary tract infection (UTI) among neonates with late-onset sepsis remains unknown.

Objectives To determine the prevalence and microbiological patterns of UTI among late-onset neonatal sepsis in Cipto Mangunkusumo Hospital.

Methods We conducted a cross-sectional study on all neonates diagnosed as suspected late-onset sepsis who underwent sepsis evaluation between 20 October 2003 - 30 April 2004. Urine specimens were collected by bladder catheterization for culture and urinalysis.

Results UTI was found in $14.9 \%$ (7/47) neonates who underwent urine culture (male: female ratio was 5:2). Six subjects who had UTI were preterm neonates, Klebsiella pneumoniae was found in both blood and urine cultures of 1 subject, while the others showed different microorganisms. Forty-five out of 47 subjects, who were suspected of late-onset sepsis, had positive blood cultures. All subjects with UTI had positive bacteriuria from Gram-stained specimen.

Conclusions The prevalence of UTI among neonates with lateonset sepsis in Cipto Mangunkusumo Hospital was $14.9 \%$. The microorganisms most frequently found in urine cultures were Pseudomonas sp., Staphylococcus epidermidis, and Klebsiella pneumoniae. Urine culture, urinalysis, and urinary Gram-stain should be performed as part of sepsis evaluation for late-onset neonatal sepsis, especially in male and preterm neonates [Pediatr Indones 2005;45:217-222].
\end{abstract}

Keywords: urinary tract infection, late-onset sepsis, neonate

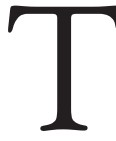

The urinary tract is a common site of infection in infants and young children. ${ }^{1}$ Urinary tract infection (UTI) in neonates often occur in association with neonatal sepsis. It is often difficult to identify whether UTI was the cause or the effect of bacteremia. ${ }^{1-3}$ The prevalence of UTI among late-onset sepsis neonates in developed countries varies from 7.4 to $25.3 \%$, with higher rates in preterm infants. $4-8$

UTI at very young age has the potential for lifelong morbidity. Progressive renal damage in early childhood may lead to hypertension and chronic renal failure later in life. ${ }^{2,9}$ The clinical manifestations of UTI in the neonatal period may vary and are nonspecific, as well as the sepsis itself. ${ }^{1-3,10}$ Urinalysis and urine culture as well as lumbar puncture for late-onset neonatal sepsis are part of a full septic-work up, ${ }^{10}$ but are not routinely done in our neonatal ward. It is important to recognize whether there is pyelonephritis in a neonate who shows clinical signs of sepsis in order to provide appropriate treatment. However, proper procedures in obtaining urine samples for culture are invasive and have potential risks for trauma and infection. 2,9 The objective of our study was to define the prevalence and microbiological pattern of UTI among neonates with late-onset sepsis in the neonatal ward of Cipto Mangunkusumo Hospital.

From the Department of Child Health, Medical School, University of Indonesia, Jakarta, Indonesia.

Reprint requests to: Novie Amelia, MD, Department of Child Health, Medical School, University of Indonesia, Cipto Mangunkusumo Hospital, Jl. Salemba No. 6, Jakarta, Indonesia. Tel. 62-21-3907742; Fax.62-21-3907743; Email: noviechozie@telkom.net. 
Methods

A cross-sectional study was conducted from October 20, 2003 to April 30, 2004 in the neonatal ward of Cipto Mangunkusumo Hospital. All infants aged 0-28 days who were diagnosed as late-onset sepsis were evaluated for UTI during septic work-up. Diagnosis of late-onset sepsis was based on the presentation of any clinical sign of sepsis at $>72$ hours of age. These clinical signs include fever, hypothermia, vomiting, dispneu/ tachypneu, cyanosis, tachycardia, hypoglycemia, jaundice, hepatomegaly, seizures, thrombocytopenia, bleeding and disseminated intravascular coagulation (DIC). Informed consents from parents or caregivers were obtained before septic work-up which included complete blood cells count, CRP (C-reactive protein), immature and total white blood cells ratio and blood cultures, urine and cerebrospinal fluid. Urine specimens were obtained by bladder catheterization. Bacterial growth of $>10^{5}$ colony-forming units $/ \mathrm{ml}$ was defined as UTI. Urinalysis consisted of leucocyte-esterase test, nitrite test, white blood cells count, and bacteria on Gram-stained specimen. The leucocyte-esterase and nitrite tests were performed using dipstick test. Leucocyte-esterase was considered positive if the dipstick showed trace, small, moderate or large. Nitrite test was considered positive if the result was + or ++ . Pyuria was defined as white blood cells more than 5 per high-power field. Bacteriuria was considered positive if any organisms were present on Gram-stained specimen.
Subjects who were born in different clinics/ hospitals and those who had contraindications for bladder cathetherization were excluded. These contraindications were severe thrombocytopenia $(<50000 \mathrm{~mL})$ or clinically/proved DIC. This study was approved by The Committee for Medical Research Ethics, Medical School, University of Indonesia.

\section{Results}

During a six-month period, there were 138 neonates who were diagnosed as late-onset sepsis but only 47 were included in this study. Of the remaining subjects with late-onset sepsis, 46 were excluded due to severe thrombocytopenia and 15 due to DIC. Informed consents could not be obtained from 25 subjects. In 5 subjects, urine specimens were inadequate for culture.

Twenty-three out of 47 subjects were preterm (mean gestasional age $32.4 \pm 1.1$ weeks) and 24 subjects were term neonates (mean gestasional age $38.7 \pm 0.2$ weeks). UTI was diagnosed in $7 / 47$ (14.9\%) neonates. Male:female ratio among neonates with UTI was 5:2, and six out of seven neonates with UTI were preterm. Six subjects with UTI aged between 3-7 days, while one subject aged 15-21 days. UTI was found in 3 subjects with birth weight $<1500$ grams and also in 3 subjects with birth weight 1500-2499 grams, while in neo-

Table 1. Characteristics of SUbJects

\begin{tabular}{lccc}
\hline Characteristics & \multicolumn{3}{c}{ Urine culture results } \\
\cline { 2 - 4 } & Positive & Negative & Total \\
\hline Age (days) & 6 & 31 & 37 \\
$\quad 3-7$ & 0 & 8 & 8 \\
$8-14$ & 1 & 0 & 1 \\
$15-21$ & 0 & 1 & 1 \\
$\quad 22-28$ & & & \\
Gestational age (weeks) & 6 & 17 & 23 \\
$\quad<37$ & 1 & 23 & 24 \\
$\quad 37-42$ & & & \\
Sex & 5 & 25 & 30 \\
$\quad$ Male & 2 & 15 & 17 \\
$\quad$ Female & & & \\
Birth weight (gram) & 3 & 6 & 9 \\
$\quad<1500$ & 3 & 14 & 17 \\
$1500-2499$ & 1 & 20 & 21 \\
$\quad 2500-3999$ & & & \\
$\quad$
\end{tabular}

218 • Paediatrica Indonesiana, Vol. 45, No. 9-10 • September - October 2005 
Novie Amelia et al: Urinary tract infection among neonatal sepsis of late-onset

TABLE 2. Microorganisms FOUND IN BLOOD AND URINE CULTURE IN NEONATES WITH UTI

\begin{tabular}{lll}
\hline No & Blood culture & Urine culture $\left(>\mathbf{1 0}^{\mathbf{5}} \mathbf{C F U} / \mathbf{m L}\right)$ \\
\hline & & \\
1. & Klebsiella pneumoniae & Klebsiella pneumoniae \\
2. & Klebsiella pneumoniae & Pseudomonas $\mathrm{sp}$. \\
3. & Klebsiella pneumoniae & Pseudomonas sp. \\
4. & Acinetobacter calcoaceticus & Pseudomonas sp. \\
5. & Acinetobacter calcoaceticus & Staphylococus epidermidis \\
6. & Acinetobacter calcoaceticus & Staphylococus epidermidis \\
7. & Enterobacter aerogenes & Staphylococus epidermidis \\
\hline
\end{tabular}

Table 3. Results of ANTiBIOtics Resistances of Microorganisms CAUSING UTI

\begin{tabular}{|c|c|c|c|c|c|c|c|}
\hline \multirow{3}{*}{ Antibiotics } & \multicolumn{7}{|c|}{ Microorganisms } \\
\hline & \multirow{2}{*}{$\begin{array}{c}\text { Klebsiella } \\
\text { pneumoniae }\end{array}$} & \multicolumn{3}{|c|}{$\begin{array}{c}\text { Staphylococcus } \\
\text { epidermidis }\end{array}$} & \multicolumn{3}{|c|}{ Pseudomonas sp } \\
\hline & & 1 & 2 & 3 & 1 & 2 & 3 \\
\hline Oxacillin & $\mathrm{R}$ & $S$ & $\mathrm{R}$ & $\mathrm{R}$ & $\mathrm{R}$ & $\mathrm{R}$ & $\mathrm{R}$ \\
\hline Ampicillin & $\mathrm{R}$ & $\mathrm{R}$ & $\mathrm{R}$ & $\mathrm{R}$ & $\mathrm{R}$ & $\mathrm{R}$ & $\mathrm{R}$ \\
\hline Chloramphenicol & $\mathrm{R}$ & $S$ & $S$ & $\mathrm{R}$ & $\mathrm{R}$ & $\mathrm{R}$ & $\mathrm{R}$ \\
\hline Gentamycin & $\mathrm{R}$ & $\mathrm{s}$ & $\mathrm{S}$ & $\mathrm{R}$ & $\mathrm{R}$ & $\mathrm{R}$ & $\mathrm{R}$ \\
\hline Nalidixic acid & $S$ & S & $\mathrm{R}$ & $\mathrm{R}$ & $\mathrm{R}$ & $\mathrm{R}$ & $\mathrm{R}$ \\
\hline Nitrofurantoin & $\mathrm{R}$ & $S$ & $S$ & $\mathrm{~S}$ & $\mathrm{R}$ & $\mathrm{R}$ & $\mathrm{R}$ \\
\hline Amikacin & $\mathrm{R}$ & $S$ & $\mathrm{R}$ & $S$ & $\mathrm{R}$ & $\mathrm{R}$ & $\mathrm{R}$ \\
\hline Ampicillin-Sulbactam & $\mathrm{R}$ & $S$ & $\mathrm{~S}$ & $\mathrm{~S}$ & $\mathrm{R}$ & $\mathrm{R}$ & $\mathrm{R}$ \\
\hline Pipemidic acid & $S$ & $\mathrm{R}$ & $\mathrm{R}$ & $\mathrm{R}$ & $\mathrm{R}$ & $\mathrm{R}$ & $\mathrm{R}$ \\
\hline Cefotaxime & $\mathrm{R}$ & $S$ & $S$ & $S$ & $\mathrm{R}$ & $\mathrm{R}$ & $\mathrm{R}$ \\
\hline Amoxicilin-clavulanic acid & $\mathrm{R}$ & $S$ & $\mathrm{R}$ & $S$ & $\mathrm{R}$ & $\mathrm{R}$ & $\mathrm{R}$ \\
\hline Ceftriaxone & $\mathrm{R}$ & $\mathrm{s}$ & $\mathrm{S}$ & $\mathrm{S}$ & $\mathrm{R}$ & $\mathrm{R}$ & $\mathrm{R}$ \\
\hline Ceftazidime & $\mathrm{R}$ & $\mathrm{R}$ & $\mathrm{R}$ & $\mathrm{R}$ & $\mathrm{R}$ & $\mathrm{R}$ & $\mathrm{R}$ \\
\hline Vancomycin & $\mathrm{R}$ & $S$ & $S$ & $S$ & $\mathrm{R}$ & $\mathrm{R}$ & $\mathrm{R}$ \\
\hline Cefepime & $\mathrm{R}$ & $S$ & $S$ & $S$ & $\mathrm{R}$ & $\mathrm{R}$ & $\mathrm{R}$ \\
\hline Fosfomycin & $\mathrm{S}$ & $S$ & $\mathrm{R}$ & $\mathrm{R}$ & $\mathrm{R}$ & $\mathrm{R}$ & $\mathrm{R}$ \\
\hline Teicoplanin & $\mathrm{R}$ & $\mathrm{s}$ & $\mathrm{S}$ & $\mathrm{R}$ & $\mathrm{R}$ & $\mathrm{R}$ & $\mathrm{R}$ \\
\hline Meropenem & $S$ & $S$ & $S$ & $S$ & $\mathrm{R}$ & $\mathrm{R}$ & $\mathrm{R}$ \\
\hline Imipenem & $\mathrm{s}$ & $\mathrm{s}$ & $\mathrm{s}$ & $\mathrm{s}$ & $\mathrm{R}$ & $\mathrm{R}$ & $\mathrm{R}$ \\
\hline Amoxicillin & $\mathrm{R}$ & $\mathrm{S}$ & $S$ & $\mathrm{R}$ & $\mathrm{R}$ & $\mathrm{R}$ & $\mathrm{R}$ \\
\hline
\end{tabular}

nates with birth weight 2500-3999 grams was only 1 subject. The characteristics of subjects is shown in Table 1.

Blood cultures were positive in 45 out of 47 neonates who showed clinical signs of sepsis. The most common microorganism isolated from blood cultures was Acinetobacter calcoaceticus (20). Other pathogens were Klebsiella pneumoniae (8), Serratia marcescens (7), Enterobacter aerogenes (6), Staphylococcus epidermidis (2), Pseudomonas sp. (1) and Serratia rubidae (1). Microorganisms isolated from urine culture of seven neonates with UTI were Pseudomonas sp. (3), Staphylococcus epidermidis (3) and Klebsiella pneumoniae (1). One subject with Klebsiella pneumoniae UTI had the same organism found in the blood culture, while the other six subjects had different organisms (Table 2).

Results of antibiotic resistance tests of the microorganisms causing UTI are shown on Table 3. Klebsiella pneumoniae was sensitive to nalidixic acid, pipemidic acid, fosfomycin, meropenem and imipenem, while the three Staphylococus epidermidis showed various sensitivities. None of the three Pseudomonas sp. were sensitive to any of the antibiotics tested (Table 3).

Urinalysis results showed pyuria in 5 out of 7 neonates with UTI, whereas leucocyte-esterase test was positive in only 3 out of 7 neonates, and nitrite test was positive in 2 out of 7 neonates with UTI. All neonates with UTI had positive bacteriuria in Gram-stained specimen. 


\section{Discussion}

Tamim et al reported that the prevalence of UTI was $25.3 \%$ in 189 subjects with late-onset neonatal sepsis (mean gestasional age of $27.5 \pm 2.5$ weeks). ${ }^{7}$ Bauer et al reported $12.2 \%$ subjects with UTI among 279 late-onset sepsis neonates (gestational age of $26 \pm 1.7$ week). ${ }^{8}$ Visser and Hall found 7.4\% subjects with UTI from 189 neonates (gestational age $33.2 \pm 1.1$ weeks) who underwent sepsis evaluation for suspected late-onset sepsis. ${ }^{4}$ Purniti reported UTI in 10 out of 35 preterm and 9 out of 52 term neonates with neonatal sepsis. ${ }^{6}$ In the present study, UTI was found in 6 out of 23 preterm and 1 out of 24 term neonates. The result was consistent with that of other studies.

Visser and Hall reported that the mean age at urine culture in neonates with UTI was $22.6 \pm 3.6$ days. ${ }^{4}$ In the present study, most of subjects with UTI (6/7) aged between 3-7 days. In our study, UTI occurred in an earlier age which is most likely due to early use of antibiotics in our neonatal ward. Most subjects in our neonatal ward had received antibiotics at $<72$ hours of age.

UTI was more prevalent in neonates with lower birth weight. ${ }^{1,8}$ Bauer reported that the prevalance of UTI among late-onset sepsis neonates with birth weight $=1000$ grams was $12.2 \%$, while in neonates with birth weight $1001-1500$ grams was $5.2 \%{ }^{8}$ In our study, UTI was found in 3 out of 9 subjects with birth weight $<1500$ grams and in 3 out of 17 subjects with birth weight 1500-2499 grams, while in neonates with birth weight 2500-3999 grams was only 1 out of 21 subjects.

During the neonatal period, UTI is more prevalent in male than in female infants., ${ }^{1,2}$ This may reflect an increased risk of UTI in young uncircumcised males, increased prevalence of urinary and renal anomalies in males, transient urodynamic dysfunction and vesicoureteral refluks that predominantly affects male infants. ${ }^{1}$ In the present study male-female ratio was $5: 2$. To et al reported a 3.7 fold higher risk of UTI in urcircumcised male infants. ${ }^{11}$ Schoen et al reported that the incidence of UTI among uncircumcised male infants was $2.15 \%$, while in circumcised infants it was only $0.22 \% .{ }^{12}$ The increased rate of UTI in the uncircumcised male is likely to be associated with periurethral bac- terial flora. ${ }^{13}$ During the first six months of life, uncircumcised males have significantly higher total urethral bacterial colony counts of uropathogenic organisms such as E. coli, Klebsiella, Enterobacter, Proteus and Pseudomonas. As age increases, the fore skin is more easily retracted and penile hygiene improves. By the age of 12 months, both the excessive periurethral flora and the incidence of UTI in uncircumcised males will almost disappear. ${ }^{14}$

The microbial pattern of neonatal UTI has changed from that observed in the 1970s compared to that of the 1990s. ${ }^{1}$ In 1969, Abbott ${ }^{15}$ reported that E. coli was the most common pathogen causing UTI in neonates in Christchurch, New Zealand. Littlewood et al ${ }^{16}$ also reported E. coli as the most frequent pathogen causing neonatal UTI in Leeds Maternity Hospital. In 1989-1992, Lohr et all7 and Davies et $\mathrm{al}^{18}$ reported that in Charlottesville and Toronto, the most common pathogens of neonatal UTI were coagulase-negative Staphylococcus, Candida sp. and Klebsiella sp. In 2003, Tamim et al reported that Candida sp. was the most common microorganism causing UTI among preterm infants with late-onset sepsis, followed by coagulase-negative Staphylococcus, Pseudomonas sp. and Klebsiella $s p . .^{7}$ In our study, the microorganisms found in urine cultures were similar to other studies in the last fifteen years. Purniti, in 2002, found E. coli as the most common pathogen of neonatal UTI in Sanglah Hospital, Bali. In this study, all subjects who received antibiotics before urine culture were excluded, ${ }^{6}$ while in our study, all but one subject had received antibiotics. The subjects with prior antibiotics had sterile urine culture. The use of broad spectrum antibiotics may change natural flora in the neonate, increasing the risk of infections by opportunistic microorganisms. ${ }^{19}$

Neonatal UTI occurs through hematogenic spread or by ascending microorganisms through the urethral meatus. ${ }^{1}$ In our study, one subject had the same microorganism found in blood and urine cultures (Klebsiella pneumoniae), while other six subjects with UTI had different microorganisms in both cultures. Bauer found only six urosepsis from 66 neonatal UTI, suggesting that ascending infection was the more common mechanism in neonatal UTI. ${ }^{8}$

Late-onset sepsis in the neonatal ward of Cipto Mangunkusumo Hospital were mostly caused by 
Gram-negative pathogens. Rinawati et al (2002) found the most common bacteria which caused lateonset neonatal sepsis in the neonatal ward Cipto Mangunkusumo Hospital were Enterobacter sp. and Klebsiella sp. (unpublished data). Our study showed Acinetobacter calcoaceticus as the major pathogen of sepsis, followed by Klebsiella pneumoniae, Serratia marcescens, Enterobacter aerogenes, Staphylococcus epidermidis, Pseudomonas sp., and Serratia rubidae. All were Gram-negative microorganisms, except Staphylococcus epidermidis. Gram-negative pathogens, as well as fungi, are associated with a lower platelet count and a more prolonged thrombocytopenia compared to Gram-positive pathogens. ${ }^{20}$ It could be a possible explanation for our findings that one-third (33.3\%) from the total 138 late-onset neonatal sepsis had severe thrombocytopenia.

Acinetobacter calcoaceticus, is a nosocomial agent with low virulency, but may cause severe infection in immunocompromised host, as well as neonates. McDonald (1998) reported an outbreak of Acinetobacter sepsis in a nursery in Bahama due to contamination from air conditioners. ${ }^{21}$

The choice of initial antibiotics for neonates with presenting signs of sepsis depends on the microbial and drug-resistance pattern in each center. ${ }^{1,10}$ Ariffin reported the pattern of antibiotic resistance among Gram-negative bacteria in the pediatric units of two hospitals in Malaysia, 2004. In this study, the commonest isolates from 200 consecutive cultures of blood, urine, sputum and swabs from probable site of infection were Klebsiella sp (36.5\%) and Pseudomonas sp. (20\%). The isolates showed lower susceptibility rates to the third generation cephalosporins $(47-62 \%)$ compared to cefepime (91\%), imipenem (90\%) and ciprofloxacin (99\%). ${ }^{22}$ In the present study, Klebsiella pneumoniae was sensitive to nalidixic acid, pipemidic acid, fosfomycin, meroponem and imipenem, while Pseudomonas sp. was resistant to all antibiotics in the resistancy test. All Staphylococcus epidermidis showed sensitivity to â-lactamase-resistant antibiotics such as ampicillinsulbactam, vancomycin, imipenem, meropenem, cefotaxime, ceftriaxone and cefepime (Table 3). There are several studies reported on causative agents of neonatal UTI, ${ }^{6-8,15,16}$ however reports about the antibiotic resistance of the microorganisms were very limited.
The gold standard in diagnosing UTI is urine culture from appropriate specimens obtained by supra pubic aspiration or bladder catheterization. The urinalysis can not substitute urine culture to document the presence of UTI, but it can be valuable for prompt initiation of antibiotics since it provides information more rapidly than does urine culture. ${ }^{23}$ The sensitivity of standard urinalysis is $82 \%(95 \%$ CI, $79-84 \%$ ) and does not vary with age in febrile children younger than 2 years. ${ }^{24}$ Lockhart et al reported higher sensitivity (94 versus 67\%, p < 0.05), specificity (92 versus 79\%, p < 0.05), positive predictive value (53 versus $23 \%, \mathrm{p}<0.05$ ) and negative predictive value (99 versus $95 \%, \mathrm{p}>0.05$ ) of urinary Gram-stained compared with urinalysis including leucocyte esterase test, nitrite test, pyuria and bacteriuria. ${ }^{25}$ In our study, bacteriuria in urinary Gram-stained specimen was found in all subjects with UTI. This finding supported other studies that reported the usefulness of urinary Gramstain in diagnosing UTI. ${ }^{23-27}$

We had several limitations in our study. The subjects represented only about one-third of the sample. Due to contraindications for bladder catheterization (severe thrombocytopenia and DIC), permission (informed consent) was not granted from parents/caregivers and therefore the urine specimens were inadequate. The high rate of subjects with severe thrombocytopenia and DIC might reflect severity of illness and the fact that most of sepsis cases in our neonatal ward were caused by Gram-negative microorganisms, which correlated with lower and prolonged thrombocytopenia. Subjects who received antibiotics, prior to urine culture examination, were not excluded in the study since urine culture was obtained during repeated septic workup due to unimproved clinical condition. However, all but two subjects had positive blood cultures which suggested that bacteremia occurred although the subjects had received antibiotics.

The prevalance of UTI among neonates with late-onset sepsis in our study was $14.9 \%$. Microorganisms isolated in urine culture were Pseudomonas sp., Staphylococcus epidermidis, and Klebsiella pneumoniae. Our findings suggested that urine culture, urinalysis, and urinary Gram-stain should be performed as part of the septic work-up for late-onset neonatal sepsis, especially in males and in 


\section{Paediatrica Indonesiana}

preterm neonates, for early detection and prompt treatment of neonatal UTI.

\section{References}

1. Klein JO. Bacterial infections of the urinary tract. In: Remington JS, Klein JO, editors. Infectious disease of the fetus and newborn infant. 5th ed. Philadelphia: WB Saunders; 2001. p. 1035-46.

2. Gonzalez R. Urinary tract infection. In: Behrman RE, Kliegman RM, Jenson HB, editors. Nelson's textbook of pediatrics. 17thed. Philadelphia: Saunders; 2004. p. 549.

3. Jones KV, Asscher AW. Urinary tract infection and vesicoureteral reflux. In: Edelmann Jr CM, editor. Pediatric Kidney Disease. 2nd ed. Boston: Little, Brown and Co; 2000.p. 1926-78.

4. Visser VE, Hall RT. Urine culture in the evaluation of suspected neonatal sepsis. J Pediatr 1979;94:635-8.

5. DiGeronimo RJ. Lack of efficacy of the urine culture as part of the initial work-up of suspected neonatal sepsis. Pediatr Infect Dis J 1992;9:764-6.

6. Purniti P S. Uji diagnostik beberapa parameter klinis untuk diagnosis ISK pada sepsis neonatorum [thesis]. Denpasar (Bali, Indonesia): Medical School, Udayana Univ.; 2002.

7. Tamim MM, Alesseh H, Aziz H. Analysis of the efficacy of urine culture as part of sepsis evaluation in the premature infant. Pediatr Infect Dis J 2003;22:805-8.

8. Bauer S, Eliakim A, Pomeranz A, Regev R, Litmanovitz I, Arnon S, et al. Urinary tract infection in very low birth weight preterm infants. Pediatr Infect Dis J 2003;22:426-9.

9. Shaw KN, Gorelick MH. Urinary tract infection in the pediatric patient. Pediatr Clin N Am 1999;46:1111-24.

10. Klein JO, Marcy M. Bacterial sepsis and meningitis. In: Remington JS, Klein JO, editors. Infectious disease of the fetus and newborn infant. 5th ed. Philadelphia: WB Saunder; 2001. p. 943-98.

11. To T, Agha M, Dick PT. Cohort study on circumcision of newborn boys and subsequent risk of urinary tract infection. Lancet 1998;352:1813-16.

12. Schoen EJ, Colby CJ, Ray GT. Newborn circumcision decreases incidence and costs of urinary tract infections during the first year of life. Pediatrics 2000;105:789-93.

13. Wiswell TE. The prepuce, urinary tract infections, and the consequences. Pediatrics 2000;105:860-1.
14. Wiswell TE, Miller GM, Gelston HM. The effect of circumcision status on periurethral bacterial flora during the first year of life. J Pediatr 1988;113:442-6.

15. Abbott GD. Neonatal bacteriuria: A prospective study of 1460 infants. BMJ 1972;1;267-9.

16. Littlewood JM, Kite P, Kite BA. Incidence of neonatal urinary tract infection. Arch Dis Child 1969;44:617-9.

17. Lohr JA, Donowitz LG, Sadler JE 3rd. Hospital acquired urinary tract infection. Pediatrics 1989;83:193-6.

18. Davies HD, Jones ELF, Sheng RY. Nosocomial urinary tract infections at a pediatric hospital. Pediatr Infect Dis J 1992;11:349-51.

19. Falcao MC, Leone CR, D’Andrea RA, Berardi R, Ono NA, Vaz VAC. Urinary tract infection in full-term newborn infants: Risk factor analysis. Rev Hosp Clin Fac Med S Paulo 2000;55:9-16.

20. Guida JD, Kunig AM, Leef KH, McKenzie SE, Paul DA. Platelet count and sepsis in very low birth weight neonates: Is there an organism-specific response? Pediatrics 2003;111:1411-15.

21. McDonald LC, Walker M, Carson L. Outbreak of Acinetobacter spp: Bloodstream infections in a nursery associated with contaminated aerosols and air conditioners. Pediatr Infect Dis J 1998;17:716-22.

22. Ariffin H, Navaratnam P, Kee TK, Balan G. Antibiotic resistance patterns in nosocomial Gram-negative bacterial infections in units with heavy antibiotic usage. J Trop Pediatr 2004;50:26-31.

23. American Academy of Pediatrics. Practice parameter: The diagnosis, treatment and evaluation of the initial urinary tract infection in febrile infants and young children. Pediatrics 1999;103:1-12.

24. Bachur R, Harper MB. Reliability of the urinalysis for predicting urinary tract infections in young febrile children. Arch Pediatr Adolesc Med 2001;155:60-5.

25. Lockhart GR, Lewander WJ, Cimini DM, Josephson SL, Linakis JG. Use of urinary Gram stain for detection of urinary tract infection in infants. Ann Emerg Med 1995;25:31-5.

26. Lohr JA, Portilla MG, Geuder TG, Dunn ML, Dudley SM. Making a presumptive diagnosis of urinary tract infection by using a urinalysis performed in an on-site laboratory. J Pediatr 1993;122:22-5.

27. Weinberg AG, Gan VN. Urine screen for bacteriuria in symptomatic pediatric outpatients. Pediatr Infect Dis J 1991;10:651-4. 